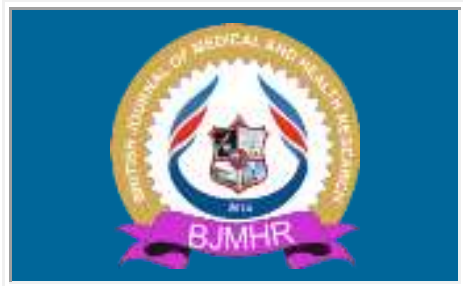

\title{
BJMHR
}

British Journal of Medical and Health Research Journal home page: www.bjmhr.com

\section{Lessons Learnt After Implementation of Community-Led-To- Total Sanitation Intervention In Busia County Kenya}

\author{
David Masinde \\ Maseno university, Kenya
}

\section{ABSTRACT}

In December 2012, Kenya government and UNICEF jointly implemented a Community-LedTotal Sanitation Intervention (CLTSI) in Busia County to tame poor sanitation that was at $42 \%$ vs $49 \%$ National. The CLTSI was to achieve total sanitation among Busia County households through sanitation behavior change. Main aim of the study was to document the lessons learnt after implementation of CLTSI in Busia County. The study focused on the implementation process of the CLTSI to draw experiences. Documenting lessons learnt helped in understanding and improving implementation of CLTSI, accounting for success (or failure) and enhancing best practice of CLTSI management before countrywide rollout. Quasi experimental design was used while multi-stage and random sampling was used to sample respondents. A total of $35(70 \%)$ of primary implementers of CLTSI participated in the study Structured questionnaire was used to collect the data. Findings show that out of 35 facilitators who implemented CLTSI, only $25(71.4 \%$ ) were trained on the rigours of CLTSI. Duration of training varied from 3 days $10(28.6 \%)$ to 5 days $15(42.9 \%)$ of which more than a half $21(60.0 \%)$ CLTSI facilitators felt training was inadequate. Challenges experienced during implementation of CLTSI included: time constraint 24 (68.6\%), transport constraint 20(57.1\%), inadequate skills 17(48.6\%), poor community mobilization 35(100.0\%), household illiteracy 29 (82.9\%), financial constraint 18 (51.9\%).Other reasons included hostile community, poor leadership 32 (91.4\%).For the purposes of rolling up the CLTSI, some lessons learnt could be adopted in order to achieve total sanitation in the country. From our evaluation study, CLTSI was found to have impacted positively to the residents of Busia County.

Keywords: Lessons learnt Community-led-To Total Sanitation Intervention. 


\section{INTRODUCTION}

Busia County was among the counties with the lowest (42\%) sanitation coverage, with more than half of the population defecating in the open. Diarrhea and cholera were among the top three diseases causing morbidity and mortality in the County, with cholera outbreaks frequently being reported (MoPHS, 2012).

Ministry of Health in partnership with UNICEF designed a participatory sanitation approach tapped Community-Led-To Total Sanitation intervention (CLTSI) a pilot intervention to tame poor sanitation in Busia County with a view of scaling-up the programme to entire Country.

The Community-Led-Total Sanitation Intervention (CLTSI) that was pioneered in 1999 by Village Education Resource Centre and Water Aid in Bangladesh. This was an innovative approach for mobilizing villages to adopt total sanitation and hygiene practices through sanitation behavior change (Kumar, 2005). With CLTSI approach, communities analyze their sanitation conditions, understand the impact of open defection on health and the environment and take collective action to adopt sanitation and hygienic practices like total use of hygienic latrines, washing hands with soap during critical times e.g. washing hands after visiting latrine, before and after handling food, after handling children feaces among others (Water Aid, 2007; Kamal and Chambers, 2008). There is a pressing need for achieving sustainable and effective sanitation coverage in Kenya. Currently, majority of villages in Busia County have been certified to have attained total $(100 \%)$ sanitation hence have adopted sanitation and hygienic practices

The CLTSI addressed itself to the pursuit of total sanitation in Kenya (MoPHS, 2010) through sanitation behavior change. The CLTSI refers to complete eradication of all indiscriminate and (1) unhygienic practices in the disposal of (2) excreta, (3) drainage and (4) solid waste. The objectives for CLTSI were divided into stages which included: Stage 1. No village in Kenya practices open defecation (OD), by 2015, improve sanitary household latrine coverage from existing $49 \%$ to $100 \%$ by 2015 , all Kenyans practice hand washing with soap at critical times by 2015 . Stage 2; and then address the environmental health risks that are posed by poor drainage and solid waste disposal by 2015-2030 (MoPHS, 2010).

The objective of this study was to document the lessons learnt after CLTSI implementation in Busia County Kenya.

\section{MATERIALS AND METHOD}

\section{Study site:}

This study was carried out in Busia County because it was among counties with lowest sanitation coverage of $42 \%$ hence NTSP was launched in 2012 as a pilot programme. It is one of the 47 Counties in Kenya, covering an area of 673.6 square $\mathrm{km}$ and lies between latitudes 
$0^{\circ} 1^{\prime} 36^{\prime \prime}$ 'South and $0^{\circ} 33^{\prime}$ North and longitudes $33^{\circ} 54^{\prime}$ '32' East and $34^{\circ} 25^{\prime}$ ' 24' ' East. The County is divided into five administrative Sub-Counties namely Township, Funyula, Matayos, Nambale and Butula, Teso North, Teso south and Samia. The Sub-Counties are further subdivided into 17 locations and 52 sub-locations. It was projected that by 2015 Busia County was to have a population of 378,649 (GoK, 2009). According to the Busia County statistics (2008), $65.99 \%$ and $61.4 \%$ of the population suffers absolute and food poverty respectively.

\section{Research design:}

Quasi experimental study design was used. Data was collected after CLTSI had been implemented. A total of 35

\section{Target population:}

The target population was stakeholders of CLTSI. They included; CLTSI beneficiaries $(28,130$ households), CLTSI implementers (30 public health officers, 15 Community Health Extension Workers, 30 Community Health Workers and UNICEF as the main sponsor.

\section{Sampling procedure:}

Multi-stage sampling design was used to sample the locations, sub-locations and villages from the four divisions of the County which had been certified by stakeholders to have attained total sanitation. Random sampling was applied to select respondents within locations, sub-locations, villages and households. The sampling frame was based on Busia County administrative boundaries. Fisher's formula (Fisher et al. 1998) was adopted to determine the sample size using sanitation coverage in Busia County of 42\% (MoPHS, 2010) and precision set at 0.03 . Using proportionate sampling, a total of 459 respondents participated in the study as shown in Table 1. Data Collection procedure: Tools that were used to collect primary data included structured questionnaires. Primary data was collected after implementation of CLTSI (September September- December 2015) About 35 implementers of CLTSI were included in the study

\section{Data analysis:}

Data was managed using statistical package for Social sciences. Descriptive statistics (frequencies, percentages) was used for analysis.

\section{Ethical consideration:}

Authority to carry out the research was obtained from Maseno University ethics and research committee (MSU/DRP/MUERC/00240/15).

\section{RESULTS AND DISCUSSION}

Findings show that out of 35 facilitators who implemented CLTSI, only 25(71.4\%) were trained on the rigours of CLTSI. Content of CLTSI training included; latrine construction and options $8(32.0 \%)$, latrine hygiene 18 (72.0\%), community triggering $22(88.0 \%)$, hand washing 
in critical times with soap (11 (44.0\%), effects of open defecation 14 (56.0\%), disposal of human excreta $10(40.0 \%)$, personal hygiene 22(88.0\%), solid waste management $23(92.0 \%)$, water storage and treatment $15(60.0 \%)$ others e.g. community capacity building and empowerment and logistics 1(2.9\%).

Duration of training varied from 3 days 10 (28.6\%) to 5 days 15 (42.9\%) of which more than a half $21(60.0 \%)$ CLTSI facilitators felt training was inadequate. While only $11(44.0 \%)$ of the facilitators were satisfied with the implementation of CLTSI process.

Reasons given for inadequate training and not satisfied with CLTSI implementation included; did not cover entire CLTSI process 22(88.0\%), poor community participation 5(20.0\%), poor facilitation $21(84.0 \%)$, overloaded content within short period of training time 22(88.0\%), poor organization and content delivery totally theoretical $21(84.0 \%)$ and poor logistics 15 $(60.0 \%)$.

Challenges experienced during implementation of CLTSI included: time constraint 24 (68.6\%), transport constraint $20(57.1 \%)$, inadequate skills $17(48.6 \%)$, poor community mobilization 35(100.0\%), household illiteracy 29 (82.9\%), financial constraint 18 (51.9\%).Other reasons included hostile community, poor leadership 32 (91.4\%). Though only 25(71.4\%) facilitators acknowledged receiving payment for three days of training, when asked amount received per day 18 (51.6\%) were paid Ksh 1500, 15 (42.9\%) Ksh 2500 and 2 (5.5\%) received Ksh 4500 per day.

Households $180(54.2 \%)$ indicated that not all community members participated in the triggering of villages during CLTSI implementation. However, majority 314 (77.3\%) of households were in agreement that CLTSI was of value to them and $329(81.0 \%)$ affirmed the personal benefit of CLTSI. More than three quarters 263(79.0\%) of respondents were in agreement about adequacy of time during implementation of CLTSI.

\section{Community participation and mobilization}

Study findings, 180(54.2\%) indicated that not all community members participated in the triggering of villages during CLTSI implementation. Members of the community including leaders were not informed in advance. Proper community mobilization at village level was not adequately done. For maximum results, all community leaders at local/village including religious, administration, political leaders and members of the community should be mobilized to participate for the success of any intervention (Khan, 2008). Sanitation is a private practice that has a public consequence (GoK, 2012). The CLTSI targets the behavior change of the entire community rather than individual households hence community participation is important. Community members through their representatives will be involved in planning and implementation of CLTSI at village level (Kar, 2005). It is only through participation that 
communities will get a sense of ownership and should, therefore, feel motivated to operate and maintain the system (Abbot and sharing, 1996, Narayan, 1995). This approach will ensure that women, as care givers understand the benefits of proper s anitation and hygiene practices. This will further guarantee sustainability of the sanitation behavior change attained.

\section{Sanitation and hygiene education and promotion}

Health education and promotion is the process of interaction between people in order to discuss their health situation, with the aim to create awareness about health status and to decide jointly how this situation can be improved" (Timmermans and de Walle, 1995: 278). It is all activities aimed at encouraging behavior change which will help to prevent water and sanitation- related diseases" (Boot and Cairncross, 1993: 33). The full potential of health benefits to communities will only be achieved if the provision of water is accompanied by hygiene promotion and sanitation. Investing in hygiene promotion to prevent such outbreaks and reduce regular disease is highly cost effective (Varley \& Bendahmane, 1997). When hygiene promotion is combined with access to improved water supply and sanitation, the estimated cost is only US\$ 3 per household per year for each averted case of diarrhoea in children under five (Sandy and Curtis, 2001). When no water and sanitation facilities are provided, the cost of promoting good hygiene is obviously higher. However, it costs only US\$ 6 per household per year to keep a child free from diarrhoea when hygiene is improved without the costs of hardware (Sandy and Curtis, 2001). Study findings indicate that the CLTSI process of triggering (time when sanitation and hygiene promotion is passed to villages) a village was half a day. This duration was inadequate to pass the hygiene promotion messages. This was compounded by inadequate training of facilitators $21(60.0 \%)$ hence poor facilitation skills. Moreover, households felt that time were not enough for triggering process 24 (68.6\%). According Boot and Gently (2001) research, health benefits from health education and promotion included, 36\% reduction in incidence of diarrhoeal from improved excreta disposal; $30 \%$ reduction in incidence of diarrhoeal in children (3-36 months) in households with flush toilets; $15 \%$ in incidence of diarrhoeal in children (3-36 months) in households with pit latrines; $40 \%$ reduction of children with stunted growth in households with flush toilets; $26 \%$ reduction of children with stunted growth in households with pit latrines; Among illiterate mothers, a 7-fold larger reduction in child mortality than with a better water supply; $33 \%$ reduction in incidence of diarrhoea from improved hygiene practices; $20 \%$ reduction in incidence of diarrhoeas from improved water quantity; 50\% reduction in 24 hours incidence of diarrhoea when water collection roundtrip is reduced from +60 to $0-5$ minutes; $5 \%$ reduction of children with stunted growth when the household has water on the premises; $15 \%$ reduction in incidence of diarrhoea from improved water quality; Elimination of guinea worms. 
The focus of hygiene promotion should be on changing key behaviours. These include hand washing after defecation and before handling food, use of latrines, and keeping water free from faecal contamination. To obtain the optimum benefits from water good hygiene, improved sanitation hardware and water supply, has to reach all households in the community (Mehra, 1997).

\section{Training of facilitators and triggering of the villages}

According to Nilinjana et al., (2012) the facilitators trained tended to use multiple and wellknown CLTSI triggering tools most of the time, while the others, non- facilitator often relied upon a single tool, i.e., social mapping. The CLTSI tools are meant to be used in a sequence, which helps to progressively build up collective realization of the repugnant consequences of poor sanitation. Findings show that out of 35 facilitators who participated in the CLTSI study, only $25(71.4 \%)$ were trained on the rigours of CLTSI. Moreover, duration of training varied from 3 days 10 (28.6\%) and 5 days 15 (42.9\%). Facilitators cited overloaded content within short period of training time 22(88.0\%), poor organization and content delivery totally theoretical 21(84.0\%) and inadequate facilitation skills 17(48.6\%). This study finding are similar with a study carried out by Joyce and Lorreta, (2009) in which the capacity of facilitators to facilitate community level triggering seemed limited as some of them were unable to clearly explain how they had implemented the triggering process at community level. The study also indicated that combined use of threats with the various tools to help them achieve total sanitation had adversely affected these communities as they were not yet $100 \%$ sanitation coverage level. For better results, a structured practical training should be conducted with the training of trainers (ToT's). This will ensure maximum realization of Total sanitation triggered villages. The poor were sometimes singled out for triggering as they were the open defecators - and this did not help either. Selective triggering hindered a communitywide build up of momentum for sanitation behavior change (Nilanjana et. al., 2012). Triggering should be collective in that all villages and their members should be involved despite the economic status, race, age and race. For sanitation is a private affair that has a public consequence (Kar, 2006). For the purpose of achieving maximum mass community presence and participation, triggering ought to be done on weekends. This will ensure all community members are present whether working, school going children, men and women.

\section{Follow-up of villages}

It was noted from the study, follow-up and monitoring was not done at all after triggering and drawing an action plan for achieving total sanitation. Follow-up and monitoring ensures sustainability of sanitation behavior change by community members and ensures there is no fall back by community members. These study findings are consistent with those of Joyce and 
Lorreta, (2009) in which it was found out that in some communities, facilitors did not undertake any follow-up visits after the triggering exercise. From the study, it was noted that there seemed no systematic follow up approach, and what needed to be done during the visits. Facilitors should follow-up on a regular basis to ensure proper sanitation and hygiene practices are sustained.

\section{Logistics and timescale}

According to Nilanjana et. al.,, (2012) a facilitator hard-pressed for time, lacking adequate resources for field work, or under-confident of his/her facilitation skills may therefore skip the use of tools other than the social map, and do it with a few community members. From the study findings, several logistical challenges were experienced that might have hindered total sanitation achievement in some villages which included time constraint 24 (68.6\%), transport constraint 20(57.1\%), poor community mobilization 35(100.0\%), household illiteracy 29 (82.9\%), financial constraint $18(51.9 \%)$ and poor leadership 32 (91.4\%). In order to trigger a national drive towards, total sanitation, there is the need for full political support to raise the profile and encourage communities. This could most likely lead to the scaling up of successes achieved in ODF communities.

\section{CONCLUSION}

The CLTSI pilot project undertaken in Busia County has demonstrated an approach that can rapidly change perception and attitude of communities towards sanitation and hygiene practices to inspire actions and take up improved services. It transforms the community perception and understanding of sanitation and builds on local practices and innovations to provide appropriate services to meet the needs and capacity of the communities. For the purposes of rolling up the CLTSI, some lessons learnt could be adopted in order to achieve total sanitation in the country. From our evaluation study, CLTSI was found to have impacted positively to the residents of Busia County.

\section{RECOMMENDATION}

1. Community participation and mobilization to ensure that all members of the community are involved in triggering process. Carrying out of CLTSI triggering process ought to be done on a weekend to include all members of the villages.

2. Sanitation and hygiene education and promotion is crucial for the purpose of creating awareness to the community members.

3. Intensive training of facilitators and triggering of the villages. This will equip the facilitators the necessary tools for triggering the villages. 
4. Follow-up and monitoring ought to be done on a regular basis by facilitators after CLTSI implementation. This will ensure sustainability of sanitation behavior change by community members and avoid fall back to poor sanitation and hygiene practices.

5. Logistics for facilitators should be well organized to ensure proper and successful implementation of CLTSI during roll-out phase in entire country.

6. Adopt National Total Sanitation as a National policy for the improvement of sanitation coverage in Kenya.

\section{REFERENCES}

1. Elliot R. and Payne K. (2005). Essentials of Economic Evaluation in Healthcare. 1stn Edition. London: Pharmaceutical Press;.

2. Esrey and Andersson (1999), Environmental Sanitation from an Ecological Systems Approach 26: (10/90 Report on Health Research, 2000. Global Forum for Health Research)

3. Esrey S., Potash JB, Roberts, L, and Shiff, C. (1991). Effects of improved water supply and sanitation on ascariasis, diarrhoea, dracunculiasis, hookworm infection, schistosomiasis, and trachoma. Bulletin of the World Health Organization, 69:609-621.

4. Feachem, R. (1984). Interventions for the control of diarrhoeal diseases among young children: promotion of personal and domestic hygiene. Bulletin of the World Health Organization, 62:467-476.

5. Ferley, J, Zmirou, D, Collin J, Charrel, M. (1986). Etude longitudinal des risquesliés à la consommation d'eaux non conformes aux normes bactériologiques. Revue $d$ ' Epidémiologie et de Santé Publique, 34:89-99.

6. Fewtrell 1, kaufman R, Kay D, Enanoria w, Haller 1, and Colford J. (2007). Water sanitation and hygiene intervention to reduce diarrhoea in less developed Countries : a systematic review and meta-analysis : The lancet infectious 2005 ; 42-25 : Pub med.

7. Gerrans, G.( 2004). Waist Deep in Waste - Reduce, Re-Use, Recycle. Spectrum; Vol. 32 (1): 32- 36.

8. GoK, (2009). Busia District development plan 2008-2012. Nairobi, Government Printers

9. Hawe, P., Degeling, D. and Hall, J. (1990). Evaluating health promotion: a health worker's guide. MacLennan and Petty: Sydney.

10. Kar, K. (2005). Practical guide to triggering CLTS. Bangladesh, Prakashan

11. Karoly L. and Lynn A. (2008).Valuing Benefits in Benefit-Cost Studies of Social Programs.|l RAND, p.42. 
12. Kar, K. (2003). Subsidy or self respect? Participatory community sanitation in Bangladesh. Bangladesh, Prakashan

13. Kamal, K. and Chambers, C. (2008). Handbook on community- Led Total Sanitation.UK, Plan International

14. Kenya Bureau of Statistics, (2014). Kenya Demographic Health Survey. Nairobi, Government printers

15. Kenya National Bureau of Statistics, (2011). Kenya Demographic and Health Survey 2008-09. Nairobi, Government Printers.

16. Kothari, C. (2004). Research methodology: methods and techniques. Bangalore, India, Prakashan

17. Kumar, C. (2004). A guide to participatory approaches to achieving total sanitation. Bangladesh, Prakashan

18. Kusek, A. and Rist, P. (2004). Ten Steps to a Results-Based Monitoring and Evaluation System. The World Bank, Washington, D.C.

19. MoPHS, (2008). Environmental sanitation and Hygiene report. Nairobi, Government printers

20. MoPHS, (2010).Ministry of health Sanitation and Hygiene status report.Nairobi, Government printers

21. MoPHS, (2012). CLTS Trainer's manual. Nairobi, Government Printers

22. Ministry of Health, (2005). National Health Sector Strategic Plan II 2005-2010. Nairobi, Government of Kenya.

23. Naidoo, J. and Willis, J. (2000). Health Promotion - Foundations for Practice. 2nd Ed. 2000, Harcourt Publishers Limited, London.

24. New Economics Foundation, (2012). A guide to social returns on investment. SROI network, UK

25. Nixon J, Stoykova B, Glanville J, Christie J, Drummond M, Kleijnen J. (2000) The U.K. NHS economic evaluation database. Economic issues in evaluations of health technology. Int J Technol Assess Health Care.; 16(3): pp.731-42.

26. Nutbeam, D. and Bauman, A. (2006). Evaluation in a nutshell: a practical guide to the evaluation of health promotion programs. McGraw-Hill: Sydney.

27. Water Supply and Sanitation Collaborative Council Working Group on Promotion of Sanitation, UK.

28. Secchi, P. (Ed.) (1999). Proceedings of Alerts and Lessons Learned: An Effective way to prevent failures and problems (Technical Report WPP-167). Noordwijk, The Netherlands: ESTEC 
29. Shadish, W. Leviton, L. and Cook. T. (1991). Foundations of Program Evaluation: Theories of Practice. Sage Publications.

30. Scott, S. Adrew. C. and Govindan, G. (2003). Sanitation and the poor. WELL, London

31. Sen, S. and Raman, R. (2006). Study of Best Practices in Rural Sanitation in India: Working towards an Open Defecation Free Rural India. Draft Report prepared for WSP-SA. New Delhi: Water and Sanitation Program, South Asia

32. SERUS, (2010). SROI-Social Return on Investment. SERUS \& SOUL, Stockholm

33. SERUS, (2011). Social Returns on Investment. SERUS, Stockholm

34. SROI Network, (2012). Aguide to Social returns on investment. UK

35. Saunders, R., Evans, M. and Joshi, P. (2005).Developing a process-evaluation plan for assessing health promotion program implementation: A how-to guide. Health Promotion Practice. 2005. 6: 134-147.

36. Timaeus 1. and Lush G. (1995). Assessment of urban environment: water supply and sanitation services New York

37. Weber, R. Aha D. and I. and Becerra F. (2001) Intelligent lessons learned systems. Expert Systems with Applications Volume 20, Issue 1, January 2001, Pages 17-34

38. White, J, (1997).Evaluation Synthesis of Rural Water and Sanitation Projects. DFID Evaluation EV 596, May 1997.

39. WHO and UNICEF, (2010). Global water and supply and sanitation assessment 2000 report. Geneva, WHO

40. WHO/UNICEF,(2009). Diarrhoea: Why children are dying and what can be done. Geneva, WHO

41. WHO, (2005).Water sanitation and health. Geneva, WHO WSP-Knowledge Links. 2005. Formative Research for IEC Manual. New Delhi: Water and Sanitation Program-South Asia

42. World Bank Operations Evaluation Department. (2004). Monitoring and Evaluation: Some tools, methods, and approaches. The World Bank, Washington, D.C.

43. World Bank. (2005). The Development Impact Evaluation (DIME) Initiative: Coordinating Impact Evaluation Work At The World Bank. World Bank: Washington, DC.

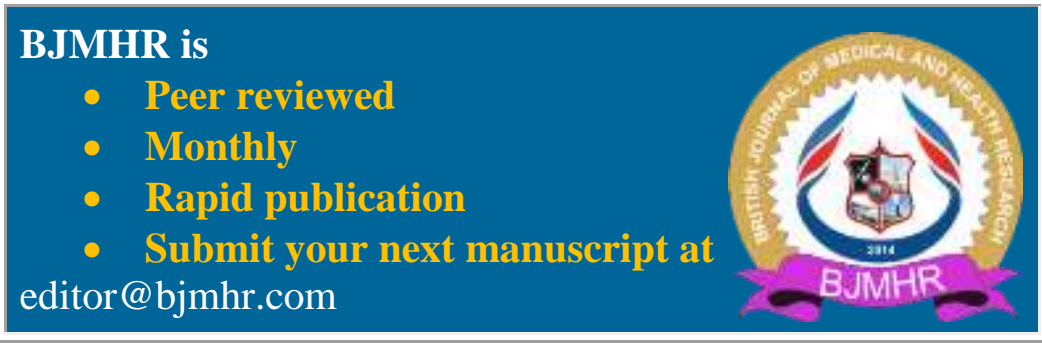

